Bull. Korean Math. Soc. 51 (2014), No. 2, pp. 479-499

http://dx.doi.org/10.4134/BKMS.2014.51.2.479

\title{
FIXED POINT SOLUTION METHODS FOR SOLVING EQUILIBRIUM PROBLEMS
}

\author{
Pham Ngoc Anh and Nguyen Duc Hien
}

\begin{abstract}
In this paper, we propose new iteration methods for finding a common point of the solution set of a pseudomonotone equilibrium problem and the solution set of a monotone equilibrium problem. The methods are based on both the extragradient-type method and the viscosity approximation method. We obtain weak convergence theorems for the sequences generated by these methods in a real Hilbert space.
\end{abstract}

\section{Introduction}

Let $\mathcal{H}$ be a real Hilbert space with inner product $\langle\cdot, \cdot\rangle$ and norm $\|\cdot\|$. Let $C$ be a nonempty closed convex subset of a real Hilbert space $\mathcal{H}$. Let $F: C \times C \rightarrow \mathcal{R}$ and $f: C \times C \rightarrow \mathcal{R}$ be two bifunctions such that $F(x, x)=0$ and $f(x, x)=0$ for all $x \in C$. We consider the equilibrium problems in the sense of Blum and Oettli (see [9]) which are presented as follows:

Find $x^{*} \in C$ such that $F\left(x^{*}, y\right) \geq 0$ for all $y \in C, \quad E P(F, C)$ and

Find $\bar{x} \in C$ such that $f(\bar{x}, y) \geq 0$ for all $y \in C . \quad E P(f, C)$ The set of solutions of the problem $\operatorname{EP}(F, C)$ is denoted by $\operatorname{Sol}(F, C)$ and the problem $E P(f, C)$ is denoted by $\operatorname{Sol}(f, C)$. Our aim in this paper is to address to the problem of finding a common solution of two equilibrium problems $E P(F, C)$ and $E P(f, C)$. Typically, this problem is stated as follows:

Find $x^{*} \in \operatorname{Sol}(F, C) \cap \operatorname{Sol}(f, C)$.

An important example of the problem (1.1) is a multiobjective optimization problem which is formulated as the following:

$$
\min \{g(x): x \in C\},
$$

Received November 16, 2012; Revised May 2, 2013

2010 Mathematics Subject Classification. 65Kxx, 90Cxx.

Key words and phrases. equilibrium problems, monotone, pseudomonotone, Lipschitztype continuous, fixed point.

This work is supported by National Foundation for Science and Technology Development of Vietnam (NAFOSTED). 
where $g_{i}: C \rightarrow \mathcal{R}(i=1,2)$ and $g(x)=\left(g_{1}(x), g_{2}(x)\right)$ for all $x \in C$. Suppose that there is a vector $\bar{y}=\left(\bar{y}_{1}, \bar{y}_{2}\right)^{T} \in \mathcal{R}^{2}$ with the property that $\bar{y}_{i}<g_{i}(x)$ for all $x \in C$ and $i=1,2$. Then, it is well-known to see that a vector $\bar{x} \in C$ is a minimal solution of the problem (1.2) if and only if there are positive real numbers $a_{1}$ and $a_{2}$ such that

$$
\max \left\{\frac{g_{i}(\bar{x})-\bar{y}_{i}}{a_{i}}: i=1,2\right\}<\max \left\{\frac{g_{i}(x)-\bar{y}_{i}}{a_{i}}: i=1,2\right\} \quad \forall x \in C, g(x) \neq g(\bar{x}) .
$$

In fact, it is not easy to define the constants $a_{1}$ and $a_{2}$. Now, for each $(x, y) \in C \times C$ we set $F(x, y)=g_{1}(y)-g_{1}(x)$ and $f(x, y)=g_{2}(y)-g_{2}(x)$. Then, we can see that the multiobjective optimization problem (1.2) is equivalent to the problem (1.1). Moreover, the problem (1.1) covers many other important problems in optimization as well as in nonlinear analysis such as variational inequalities, the nonlinear complementary problem, the nonlinear optimization problem, just to name a few (see $[1,6,15,17]$ ). On the other hand, it is rather convenient for reformulating many practical problems in economic, transportation and engineering (see $[14,16])$.

We recall that the bifunction $f$ is called monotone on $C$, if

$$
f(x, y)+f(y, x) \leq 0 \quad \forall x, y \in C ;
$$

pseudomonotone on $C$, if

$$
f(x, y) \geq 0 \text { implies } f(y, x) \leq 0 \quad \forall x, y \in C ;
$$

Lipschitz-type continuous on $C$ with constants $c_{1}>0$ and $c_{2}>0$ (see [16]), if

$$
f(x, y)+f(y, z) \geq f(x, z)-c_{1}\|x-y\|^{2}-c_{2}\|y-z\|^{2} \forall x, y, z \in C .
$$

In recent years, the problem to solve equilibrium problems becomes an attractive field for many researchers. Methods for solving the problems have studied extensively in many different ways. The proximal point method was first extended by Moudafi in [17] to equilibrium problems with monotone bifunctions. In [15], Konnov used the proximal point method for solving the equilibrium problems with weakly monotone bifunctions in a real Hilbert space. Also in the framework of proximal point methods, Nguyen et al. in [18] developed a bundle algorithm for solving the equilibrium problems where the bifunctions satisfy a certain cocoercivity condition. Extended to the methods of Fukushima in [13] for variational inequalities, Mastroeni in [16] proposed the gap function method for equilibrium problems where the gap function is introduced to convert an equilibrium problem into an optimization problem. Then, the convergence is established under continuously differentiable and strongly monotone assumptions of the bifunction. Recently, Anh et al. in [5] introduced an Armijo-type method for pseudomonotone equilibrium problems and fixed point problems. The method is based on the auxiliary problem principle and the Armijo-type linesearch techniques. Then, convergent properties of the method are established, among them the global convergence is proved under pseudomonotone assumptions of the bifunction and without Lipschitz-type 
continuous conditions. This technique also has extensively developed by many authors for solving equilibrium problems and others (see $[2,5,7,11,19,20]$ ).

Motivated by fixed point techniques of Takahashi and Takahashi in [21] and an improvement set of extragradient-type iteration methods in [5], we introduce new iteration algorithms for finding a common of the solution set of an equilibrium problem with a monotone bifunction and the solution set of a pseudomonotone equilibrium problem. In the first one, the second equilibrium problem is not required to satisfy any monotonicity property, but it must satisfy a certain Lipschitz-type continuous condition. To avoid this requirement, we propose linesearch procedures commonly used in variational inequalities to obtain projection-type algorithms for solving the problem (1.1). We show that all of the iterative sequences generated by this algorithm weakly converge to the common element in a real Hilbert space.

\section{Preliminaries}

Let $C$ be a nonempty closed convex subset of a real Hilbert space $\mathcal{H}$. We write $x^{n} \rightarrow x$ to indicate that the sequence $\left\{x^{n}\right\}$ weakly converges to $x$ as $n \rightarrow \infty, x^{n} \rightarrow x$ implies that $\left\{x^{n}\right\}$ strongly converges to $x$. For any $x \in \mathcal{H}$, there exists a nearest point in $C$, denoted by $\operatorname{Pr}_{C}(x)$, such that

$$
\left\|x-\operatorname{Pr}_{C}(x)\right\| \leq\|x-y\| \quad \forall y \in C .
$$

$\operatorname{Pr}_{C}$ is called the metric projection of $\mathcal{H}$ to $C$. It is well known that $\operatorname{Pr}_{C}$ satisfies the following properties:

$$
\begin{aligned}
& \left\langle x-y, \operatorname{Pr}_{C}(x)-\operatorname{Pr}_{C}(y)\right\rangle \geq\left\|\operatorname{Pr}_{C}(x)-\operatorname{Pr}_{C}(y)\right\|^{2} \forall x, y \in \mathcal{H}, \\
& \left\langle x-\operatorname{Pr}_{C}(x), \operatorname{Pr}_{C}(x)-y\right\rangle \geq 0 \quad \forall x \in \mathcal{H}, y \in C, \\
& \|x-y\|^{2} \geq\left\|x-\operatorname{Pr}_{C}(x)\right\|^{2}+\left\|y-\operatorname{Pr}_{C}(x)\right\|^{2} \forall x \in \mathcal{H}, y \in C .
\end{aligned}
$$

For solving the problem (1.1) with two bifunctions $F$ and $f$, let us assume that $F$ and $f$ satisfy the following conditions:

$\left(A_{1}\right) F$ is monotone on $C$;

$\left(A_{2}\right)$ for each $x \in C, F(x, \cdot)$ is lower semicontinuous and convex on $C$;

$\left(A_{3}\right)$ for each $x, y, z \in C$,

$$
\lim _{\lambda \rightarrow 0^{+}} F(\lambda z+(1-\lambda) x, y) \leq F(x, y)
$$

$\left(A_{4}\right) f$ is pseudomonotone on $C$;

$\left(A_{5}\right)$ for each $x \in C, f(x, \cdot)$ is convex on $C$ and $f$ is weak continuous on $C$ :

$\left(A_{6}\right) \operatorname{Sol}(F, C) \cap \operatorname{Sol}(f, C) \neq \emptyset$.

A mapping $S: C \rightarrow C$ is called nonexpansive, if $\|S(x)-S(y)\| \leq\|x-y\|$ for all $x, y \in C$. For finding a common point of the set of fixed points of $S$ and the solution set of the equilibrium problem $\operatorname{EP}(f, C)$, Takahashi and Takahashi in [21] first introduced an iterative scheme by the viscosity approximation method. 
The iterative sequence $\left\{x^{k}\right\}$ is defined by:

$$
\left\{\begin{array}{l}
x^{0} \in \mathcal{H}, \\
\text { Find } u^{k} \in C \text { such that } f\left(u^{k}, y\right)+\frac{1}{r_{k}}\left\langle y-u^{k}, u^{k}-x^{k}\right\rangle \geq 0 \quad \forall y \in C, \\
x^{k+1}=\alpha_{k} g\left(x^{k}\right)+\left(1-\alpha_{k}\right) S\left(u^{k}\right) \quad \forall k \geq 0,
\end{array}\right.
$$

where $g$ is a contractive mapping of $\mathcal{H}$ into itself. The authors showed that under certain conditions over $\left\{\alpha_{k}\right\}$ and $\left\{r_{k}\right\}$, sequences $\left\{x^{k}\right\}$ and $\left\{u^{k}\right\}$ strongly converge to $z=\operatorname{Pr}_{\operatorname{Sol}(f, C) \cap F i x(S)}(g(z))$. Recently, iterative methods for finding a common element of the set of solutions of equilibrium problems and the set of fixed points of a nonexpansive mapping have further developed by many authors (see [3, 8, 10, 22, 21] and the references quoted therein).

A self-mapping $S: C \rightarrow C$ is called a strict pseudocontraction, if there exists a constant $0 \leq L<1$ such that

$$
\|S(x)-S(y)\|^{2} \leq\|x-y\|^{2}+L\|(I-S)(x)-(I-S)(y)\|^{2} \forall x, y \in C,
$$

where $I$ is the identity mapping on $C$. In [5], Anh and Hien introduced an Armijo-type iteration method for finding a common element of the set of fixed points of strict pseudocontractions $S_{i}(i=1,2, \ldots, p)$ and the set of solutions of the problem $E P(f, C)$ for the pseudomonotone bifunction $f$ without Lipschitztype continuous conditions. The iterative process is based on the extragradient method and Armijo-type linesearch techniques as the following:

Step 0. Choose $x^{0} \in C$.

Step 1. Solve the strongly convex problem

$$
\begin{aligned}
& y^{k}=\operatorname{argmin}\left\{f\left(x^{k}, y\right)+\frac{\beta}{2}\left\|y-x^{k}\right\|^{2}: y \in C\right\} \\
& \text { and set } r\left(x^{k}\right)=x^{k}-y^{k} . \\
& \text { If }\left\|r\left(x^{k}\right)\right\| \neq 0 \text { then go to Step } 1 .
\end{aligned}
$$

Otherwise, set $w^{k}=x^{k}$ and go to Step 2 .

Step 2. Find the smallest positive integer number $m_{k}$ such that

$$
f\left(x^{k}-\gamma^{m_{k}} r\left(x^{k}\right), y^{k}\right) \leq-\sigma\left\|r\left(x^{k}\right)\right\|^{2} .
$$

Step 3. Compute $w^{k}=\operatorname{Pr}_{C \cap H_{k}}\left(x^{k}\right)$,

where $z^{k}=x^{k}-\gamma^{m_{k}} r\left(x^{k}\right), v^{k} \in \partial_{2} f\left(z^{k}, z^{k}\right)$

and $H_{k}=\left\{x \in \mathcal{H}:\left\langle v^{k}, x-z^{k}\right\rangle \leq 0\right\}$, and go to Step 3 .

Step 4. Compute $x^{k+1}=\alpha_{k} w^{k}+\left(1-\alpha_{k}\right) \sum_{i=1}^{p} \lambda_{k, i} S_{i}\left(w^{k}\right), k:=k+1$, go back to Step 1.

Under appropriate assumptions on the parameters, the authors showed that the sequences $\left\{x^{k}\right\},\left\{y^{k}\right\}$ and $\left\{w^{k}\right\}$ weakly converge to the point $x^{*}$, where

$$
x^{*}=\lim _{k \rightarrow \infty} \operatorname{Pr}_{\cap_{i=1}^{p}} \operatorname{Fix}\left(S_{i}, C\right) \cap \operatorname{Sol}(f, C)\left(x^{k}\right) .
$$


In this paper, we propose new iteration methods for finding a common point of the set $\operatorname{Sol}(F, C) \cap \operatorname{Sol}(f, C)$. These methods can be considered as an improvement of the viscosity approximation method in [21] and Armijo-type linesearch techniques in [5]. Then, the algorithms are modified by projecting on a suitable convex set to obtain a new variant which possesses a better convergence property. The first algorithm is now described as follows.

Algorithm 2.1. Step 0 . Choose $x^{0} \in C, k:=0$, positive sequences $\left\{\lambda_{k}\right\},\left\{\beta_{k}\right\}$ and $\left\{\alpha_{k}\right\}$ such that $\alpha_{k} \in[0,1]$ for all $k \geq 0$.

Step 1. Solve the auxiliary equilibrium problems and the strongly convex programs:

Finding $y^{k} \in C$ such that $F\left(y^{k}, y\right)+\frac{1}{\beta_{k}}\left\langle y-y^{k}, y^{k}-x^{k}\right\rangle \geq 0 \forall y \in C$,

$$
\begin{aligned}
& z^{k}=\operatorname{argmin}\left\{\lambda_{k} f\left(y^{k}, z\right)+\frac{1}{2}\left\|z-y^{k}\right\|^{2}: y \in C\right\}, \\
& t^{k}=\operatorname{argmin}\left\{\lambda_{k} f\left(z^{k}, t\right)+\frac{1}{2}\left\|t-y^{k}\right\|^{2}: y \in C\right\},
\end{aligned}
$$$$
x^{k+1}:=\alpha_{k} g\left(x^{k}\right)+\left(1-\alpha_{k}\right) t^{k} \text {. }
$$$$
\text { If } y^{k}=x^{k} \text { and } z^{k}=y^{k} \text { then STOP. Otherwise, go to Step } 2 \text {. }
$$

Step 2. Set $k:=k+1$, and return to Step 1 .

The main task of Algorithm 2.1 is to solve the auxiliary equilibrium problem (2.4) and two strongly convex programming problems (2.5)-(2.6) at Step 1. Note that problems (2.5) and (2.6) are strongly convex and $C$ is nonempty, they are uniquely solvable.

For each $\beta>0$, Combettes and Hirstoaga in [12] defined the solution mapping

$$
T_{\beta}(x):=\left\{\bar{x} \in C: F(\bar{x}, y)+\frac{1}{\beta}\langle y-\bar{x}, \bar{x}-x\rangle \geq 0 \quad \forall y \in C\right\},
$$

and the authors showed that $\bar{x}$ is a solution to the problem $\operatorname{EP}(F, C)$ is and only if its a fixed point of the mapping $T_{\beta}$. With assumption $\left(A_{1}\right)$ and for each $x \in C$, the mapping $F_{x}(t, y):=F(t, y)+\frac{1}{\beta}\langle y-t, t-x\rangle$ is strongly monotone on $C$, then the mapping $T_{\beta}$ is single-valued. Otherwise, since $x^{*}$ is a solution to the problem $E P(f, C)$ if and only if its a fixed point of the solution mapping $S$, where $S$ is defined by

$$
S(x):=\operatorname{argmin}\left\{\lambda f(x, t)+\frac{1}{2}\|t-x\|^{2}: y \in C\right\}
$$

for each $x \in C$ and $\lambda>0$. So that if $y^{k}=x^{k}$ and $z^{k}=y^{k}$, then $x^{k}$ is the common solution of two sets $\operatorname{Sol}(F, C)$ and $\operatorname{Sol}(f, C)$. We can talk that $x^{k}$ is an $\epsilon$-solution to the problem (1.1) with the tolerance $\epsilon>0$, if $\left\|x^{k}-y^{k}\right\| \leq \epsilon$ and $\left\|y^{k}-t^{k}\right\| \leq \epsilon$. In the next algorithm, we extended the algorithms in [21] and [5] for finding a common solution of the set $\operatorname{Sol}(F, C) \cap \operatorname{Sol}(f, C)$ to obtain 
a weakly convergence algorithm. This algorithm is similar to Algorithm 2.1, where an augmented step will be added to Algorithm 2.1 and obtain a new variant of the iterative algorithm in [4]. The algorithm is described as follows.

Algorithm 2.2. Step 0 . Choose $x^{0} \in C, k:=0, \gamma \in(0,1)$, positive sequences $\left\{\lambda_{k}\right\},\left\{\beta_{k}\right\}$ and $\left\{\alpha_{k}\right\}$ such that $\alpha_{k} \in[0,1]$ for all $k \geq 0$. Take $\sigma \in\left(0, \frac{\beta}{2}\right)$.

Step 1. Solve the auxiliary equilibrium problem:

(2.8) Finding $y^{k} \in C$ such that $F\left(y^{k}, y\right)+\frac{1}{\beta_{k}}\left\langle y-y^{k}, y^{k}-x^{k}\right\rangle \geq 0 \forall y \in C$.

Step 2. Solve the strongly convex program:

$$
\begin{aligned}
& z^{k}=\operatorname{argmin}\left\{\lambda_{k} f\left(y^{k}, z\right)+\frac{1}{2}\left\|z-y^{k}\right\|^{2}: y \in C\right\} . \\
& \text { If } y^{k}=x^{k} \text { and } z^{k}=y^{k} \text { then STOP. } \\
& \text { If } y^{k} \neq x^{k} \text { and } z^{k}=y^{k} \text { then set } w^{k}=y^{k} \\
& \text { and go to Step } 4 \text {. Otherwise, go to Step } 3 .
\end{aligned}
$$

Step 3. Find the smallest nonnegative integer $m_{k}$ such that

$$
\begin{aligned}
& f\left(y^{k}-\gamma^{m_{k}} r\left(y^{k}\right), z^{k}\right) \leq-\sigma\left\|r\left(y^{k}\right)\right\|^{2} \text {, where } r\left(y^{k}\right):=y^{k}-z^{k} . \\
& \text { Set } \bar{z}^{k}=y^{k}-\gamma^{m_{k}} r\left(y^{k}\right) . \\
& \text { Compute } w^{k}:=\operatorname{Pr}_{C \cap H_{k}}\left(x^{k}\right), \\
& \text { where } v^{k} \in \partial f\left(\bar{z}^{k}, \cdot\right)\left(\bar{z}^{k}\right) \text { and } H_{k}:=\left\{x \in \mathcal{H}:\left\langle v^{k}, x-\bar{z}^{k}\right\rangle \leq 0\right\} .
\end{aligned}
$$

Step 4. Compute $x^{k+1}=\alpha_{k} x^{k}+\left(1-\alpha_{k}\right) w^{k}$.

Set $k:=k+1$, and return to Step 1 .

To investigate the convergence of this scheme, we recall the following technical lemmas which will be used in the sequel.

Lemma 2.3 (see [4], Lemma 3.1). Let $C$ be a nonempty closed convex subset of a real Hilbert space $\mathcal{H}$. Let $f: C \times C \rightarrow \mathcal{R}$ be a pseudomonotone, Lipschitztype continuous bifunction with constants $c_{1}>0$ and $c_{2}>0$. For each $x \in C$, let $f(x, \cdot)$ be convex and subdifferentiable on $C$. Suppose that the sequences $\left\{y^{k}\right\},\left\{z^{k}\right\},\left\{t^{k}\right\}$ generated by Schemes (2.5) and (2.6). For each $x^{*} \in \operatorname{Sol}(f, C)$, we have

$\left\|t^{k}-x^{*}\right\|^{2} \leq\left\|y^{k}-x^{*}\right\|^{2}-\left(1-2 \lambda_{k} c_{1}\right)\left\|y^{k}-z^{k}\right\|^{2}-\left(1-2 \lambda_{k} c_{2}\right)\left\|z^{k}-t^{k}\right\|^{2} \quad \forall k \geq 0$.

Lemma 2.4 (see [10], Lemma 2.1). Let $\left\{a_{k}\right\},\left\{b_{k}\right\}$ and $\left\{c_{k}\right\}$ be three sequences of nonnegative real numbers satisfying the inequality

$$
a_{k+1} \leq\left(1+b_{k}\right) a_{k}+c_{k},
$$

for some integer $k \geq 1$, where $\sum_{k=1}^{\infty} b_{k}<\infty$ and $\sum_{k=1}^{\infty} c_{k}<\infty$. Then, $\lim _{k \rightarrow \infty} a_{k}$ exists. 
FIXED POINT SOLUTION METHODS FOR SOLVING EQUILIBRIUM PROBLEMS 485

Lemma 2.5 (see [12]). Let $F: C \times C \rightarrow \mathcal{R}$ satisfy the assumptions $A_{1}-A_{4}$, $\beta>0$ and the mapping $T_{\beta}$ is defined by (2.7). Then, the following hold:

(i) $T_{\beta}$ is single-valued;

(ii) $T_{\beta}$ is firmly nonexpansive, i.e.,

$$
\left\|T_{\beta}(x)-T_{\beta}(y)\right\|^{2} \leq\left\langle T_{\beta}(x)-T_{\beta}(y), x-y\right\rangle \quad \forall x, y \in C ;
$$

(iii) the fixed point set of $T_{\beta}$ is equivalent to $\operatorname{Sol}(F, C)$;

(iv) the solution set $\operatorname{Sol}(F, C)$ is closed and convex.

Lemma 2.6 (see [22], Lemma 3.2). Let $\mathcal{H}$ be a real Hilbert space and let $C$ be a nonempty, closed and convex subset of $\mathcal{H}$. Let the sequence $\left\{x^{k}\right\} \subset \mathcal{H}$ be Fejer-monotone with respect to $C$, i.e., for every $u \in D$,

$$
\left\|x^{k+1}-u\right\| \leq\left\|x^{k}-u\right\| \quad \forall k \geq 0 .
$$

Then, $\left\{\operatorname{Pr}_{C}\left(x^{k}\right)\right\}$ strongly converges to some $z \in C$.

\section{Convergent theorems}

Now, we prove the main convergence theorems.

Theorem 3.1. Suppose that Assumptions $A_{1}-A_{6}$ are satisfied, $f$ is Lipschitztype continuous on $C$ with constants $c_{1}>0, c_{2}>0, x^{0} \in C, \lambda$ and two sequences $\left\{\lambda_{k}\right\},\left\{\alpha_{k}\right\}$ satisfy the following restrictions:

$$
\left\{\begin{array}{l}
0<\delta<\frac{1}{\sqrt{2}}, \\
\alpha_{k} \in(0,1), \sum_{k=0}^{\infty} \alpha_{k}<\infty \\
\left\{\lambda_{k}\right\} \subset[a, b] \text { for some } a, b \in\left(0, \frac{1}{L}\right), \text { where } L=\max \left\{2 c_{1}, 2 c_{2}\right\}
\end{array}\right.
$$

Then, the sequences $\left\{x^{k}\right\},\left\{y^{k}\right\},\left\{z^{k}\right\}$ and $\left\{t^{k}\right\}$ generated by Algorithm 2.1 weakly converge to the same point $x^{*} \in \operatorname{Sol}(F, C) \cap \operatorname{Sol}(f, C)$.

The proof of this theorem is divided into several steps.

Step 1. Claim that

$$
\lim _{k \rightarrow \infty}\left\|y^{k}-t^{k}\right\|=\lim _{k \rightarrow \infty}\left\|y^{k}-z^{k}\right\|=\lim _{k \rightarrow \infty}\left\|y^{k}-x^{k}\right\|=0 .
$$

Proof of Step 1. Let $x^{*} \in \operatorname{Sol}(F, C) \cap \operatorname{Sol}(f, C)$, and $\left\{T_{\beta_{k}}\right\}$ be a sequence of the mappings defined as in Lemma 2.5 and $y^{k}$ defined by (2.4). Then, $x^{*}$ is the unique solution to the strongly monotone equilibrium problem:

$$
F\left(x^{*}, y\right)+\frac{1}{\beta_{k}}\left\langle y-x^{*}, x^{*}-x^{k}\right\rangle \geq 0 \quad \forall y \in C .
$$

This means that $x^{*}=T_{\beta_{k}}\left(x^{*}\right)$. For any $k \geq 0$, we get

$$
\left\|y^{k}-x^{*}\right\|=\left\|T_{\beta_{k}}\left(x^{k}\right)-T_{\beta_{k}}\left(x^{*}\right)\right\| \leq\left\|x^{k}-x^{*}\right\| .
$$


For each $x^{*} \in \operatorname{Sol}(F, C) \cap \operatorname{Sol}(f, C)$, it follows from $x^{k+1}=\alpha_{k} g\left(x^{k}\right)+\left(1-\alpha_{k}\right) t^{k}$, (3.2), Lemma 2.3 and $\delta \in\left(0, \frac{1}{2}\right)$ that

$$
\begin{aligned}
& \left\|x^{k+1}-x^{*}\right\|^{2} \\
= & \left\|\alpha_{k}\left(g\left(x^{k}\right)-x^{*}\right)+\left(1-\alpha_{k}\right)\left(t^{k}-x^{*}\right)\right\|^{2} \\
\leq & \alpha_{k}\left\|g\left(x^{k}\right)-x^{*}\right\|^{2}+\left(1-\alpha_{k}\right)\left\|t^{k}-x^{*}\right\|^{2} \\
= & \alpha_{k}\left\|\left(g\left(x^{k}\right)-g\left(x^{*}\right)\right)+\left(g\left(x^{*}\right)-x^{*}\right)\right\|^{2}+\left(1-\alpha_{k}\right)\left\|t^{k}-x^{*}\right\|^{2} \\
\leq & 2 \alpha_{k}\left\|g\left(x^{k}\right)-g\left(x^{*}\right)\right\|^{2}+2 \alpha_{k}\left\|g\left(x^{*}\right)-x^{*}\right\|^{2}+\left(1-\alpha_{k}\right)\left\|t^{k}-x^{*}\right\|^{2} \\
\leq & 2 \delta^{2} \alpha_{k}\left\|x^{k}-x^{*}\right\|^{2}+2 \alpha_{k}\left\|g\left(x^{*}\right)-x^{*}\right\|^{2}+\left(1-\alpha_{k}\right)\left\|t^{k}-x^{*}\right\|^{2} \\
\leq & 2 \delta^{2} \alpha_{k}\left\|x^{k}-x^{*}\right\|^{2}+2 \alpha_{k}\left\|g\left(x^{*}\right)-x^{*}\right\|^{2}+\left(1-\alpha_{k}\right)\left\|y^{k}-x^{*}\right\|^{2} \\
& -\left(1-\alpha_{k}\right)\left(1-2 \lambda_{k} c_{1}\right)\left\|y^{k}-z^{k}\right\|^{2}-\left(1-\alpha_{k}\right)\left(1-2 \lambda_{k} c_{2}\right)\left\|z^{k}-t^{k}\right\|^{2} \\
\leq & {\left[1-\alpha_{k}\left(1-2 \delta^{2}\right)\right]\left\|x^{k}-x^{*}\right\|^{2}+2 \alpha_{k}\left\|g\left(x^{*}\right)-x^{*}\right\|^{2} } \\
& -\left(1-\alpha_{k}\right)\left(1-2 \lambda_{k} c_{1}\right)\left\|y^{k}-z^{k}\right\|^{2}-\left(1-\alpha_{k}\right)\left(1-2 \lambda_{k} c_{2}\right)\left\|z^{k}-t^{k}\right\|^{2} .
\end{aligned}
$$

Then, using Lemma 2.4 and $\sum_{k=1}^{\infty} \alpha_{k}<\infty$, we have the existence of $c:=$ $\lim _{k \rightarrow \infty}\left\|x^{k}-x^{*}\right\|^{2}$ and

$$
\begin{aligned}
& {\left[1-\alpha_{k}\left(1-2 \delta^{2}\right)\right]\left(1-2 b c_{1}\right)\left\|y^{k}-z^{k}\right\|^{2} } \\
\leq & \left(1-\alpha_{k}\right)\left(1-2 \lambda_{k} c_{1}\right)\left\|y^{k}-z^{k}\right\|^{2} \\
\leq & \left\|x^{k}-x^{*}\right\|^{2}-\left\|x^{k+1}-x^{*}\right\|^{2}+2 \alpha_{k}\left\|g\left(x^{*}\right)-x^{*}\right\|^{2} \\
\rightarrow & 0 \text { as } k \rightarrow \infty,
\end{aligned}
$$

and

$$
\lim _{k \rightarrow \infty}\left\|z^{k}-y^{k}\right\|=0 .
$$

By the similar way, also

$$
\lim _{k \rightarrow \infty}\left\|z^{k}-t^{k}\right\|=0 .
$$

Combining this, (3.5) and the inequality $\left\|y^{k}-t^{k}\right\| \leq\left\|y^{k}-z^{k}\right\|+\left\|z^{k}-t^{k}\right\|$, we have

By Lemma 2.5, we have

$$
\lim _{k \rightarrow \infty}\left\|y^{k}-t^{k}\right\|=0 .
$$

$$
\begin{aligned}
\left\|y^{k}-x^{*}\right\|^{2} & =\left\|T_{\beta_{k}}\left(x^{k}\right)-T_{\beta_{k}}\left(x^{*}\right)\right\|^{2} \\
& \leq\left\langle T_{\beta_{k}}\left(x^{k}\right)-T_{\beta_{k}}\left(x^{*}\right), x^{k}-x^{*}\right\rangle \\
& =\left\langle y^{k}-x^{*}, x^{k}-x^{*}\right\rangle \\
& =\frac{1}{2}\left(\left\|y^{k}-x^{*}\right\|^{2}+\left\|x^{k}-x^{*}\right\|^{2}-\left\|y^{k}-x^{k}\right\|^{2}\right),
\end{aligned}
$$

and hence

$$
\left\|y^{k}-x^{*}\right\|^{2} \leq\left\|x^{k}-x^{*}\right\|^{2}-\left\|y^{k}-x^{k}\right\|^{2} .
$$


Then, from $x^{k+1}=\alpha_{k} g\left(x^{k}\right)+\left(1-\alpha_{k}\right) t^{k}$ and Lemma 2.3, it follows that

$$
\begin{aligned}
\left\|x^{k+1}-x^{*}\right\|^{2} & =\left\|\alpha_{k} g\left(x^{k}\right)+\left(1-\alpha_{k}\right) t^{k}-x^{*}\right\|^{2} \\
& \leq \alpha_{k}\left\|g\left(x^{k}\right)-x^{*}\right\|^{2}+\left(1-\alpha_{k}\right)\left\|t^{k}-x^{*}\right\|^{2} \\
& \leq \alpha_{k}\left\|g\left(x^{k}\right)-x^{*}\right\|^{2}+\left(1-\alpha_{k}\right)\left\|y^{k}-x^{*}\right\|^{2} \\
& \leq \alpha_{k}\left\|g\left(x^{k}\right)-x^{*}\right\|^{2}+\left(1-\alpha_{k}\right)\left(\left\|x^{k}-x^{*}\right\|^{2}-\left\|y^{k}-x^{k}\right\|^{2}\right) .
\end{aligned}
$$

Then

$$
\left(1-\alpha_{k}\right)\left\|y^{k}-x^{k}\right\|^{2} \leq \alpha_{k}\left\|g\left(x^{k}\right)-x^{*}\right\|^{2}+\left(1-\alpha_{k}\right)\left\|x^{k}-x^{*}\right\|^{2}-\left\|x^{k+1}-x^{*}\right\|^{2} .
$$

Combining this, $\left\{\alpha_{k}\right\} \subset(0,1), \sum_{k \rightarrow \infty}^{\infty} \alpha_{k}<\infty$ and $\lim _{k \rightarrow \infty}\left\|x^{k}-x^{*}\right\|^{2}=c$, we get

$$
\lim _{k \rightarrow \infty}\left\|x^{k}-y^{k}\right\|=0
$$

By Step 1, we have $c=\lim _{k \rightarrow \infty}\left\|x^{k}-x^{*}\right\|^{2}$ and hence the sequence $\left\{x^{k}\right\}$ is bounded. So, there exists a subsequence $\left\{x^{k_{j}}\right\}$ such that the subsequence weakly converges to $\bar{t}$.

Step 2. Claim that the sequences $\left\{x^{k}\right\},\left\{y^{k}\right\}$ and $\left\{t^{k}\right\}$ weakly converge to the same point $\bar{t} \in \operatorname{Sol}(F, C) \cap \operatorname{Sol}(f, C)$.

Proof of Step 2. By Step 1, we also have

$$
y^{k_{i}} \rightarrow \bar{t}, z^{k_{i}} \rightarrow \bar{t}, t^{k_{i}} \rightarrow \bar{t}
$$

Since $z^{k}$ is the unique solution of the strongly convex problem

$$
\min \left\{\frac{1}{2}\left\|y-y^{k}\right\|^{2}+f\left(y^{k}, y\right): y \in C\right\},
$$

we have

$$
0 \in \partial\left(\lambda_{k} f\left(y^{k}, y\right)+\frac{1}{2}\left\|y-y^{k}\right\|^{2}\right)\left(y^{k}\right)+N_{C}\left(z^{k}\right) .
$$

This follows that

$$
0=\lambda_{k} w+z^{k}-y^{k}+w^{k}
$$

where $w \in \partial f\left(y^{k}, \cdot\right)\left(z^{k}\right)$ and $w^{k} \in N_{C}\left(z^{k}\right)$. By the definition of the normal cone $N_{C}$, we have

$$
\left\langle z^{k}-y^{k}, y-z^{k}\right\rangle \geq \lambda_{k}\left\langle w, z^{k}-y\right\rangle \quad \forall y \in C .
$$

On the other hand, since $f\left(y^{k}, \cdot\right)$ is subdifferentiable on $C$, by the well-known Moreau-Rockafellar theorem, there exists $w \in \partial f\left(y^{k}, \cdot\right)\left(z^{k}\right)$ such that

$$
f\left(y^{k}, y\right)-f\left(y^{k}, z^{k}\right) \geq\left\langle w, y-z^{k}\right\rangle \quad \forall y \in C .
$$

Combining this with (3.7), we have

$$
\lambda_{k}\left(f\left(y^{k}, y\right)-f\left(y^{k}, z^{k}\right)\right) \geq\left\langle z^{k}-y^{k}, z^{k}-y\right\rangle \quad \forall y \in C .
$$

Hence

$$
\lambda_{k_{i}}\left(f\left(y^{k_{i}}, y\right)-f\left(y^{k_{i}}, z^{k_{i}}\right)\right) \geq\left\langle z^{k_{i}}-y^{k_{i}}, z^{k_{i}}-y\right\rangle \quad \forall y \in C .
$$


Then, using $\left\{\lambda_{k}\right\} \subset[a, b] \subset\left(0, \frac{1}{L}\right)$ and the weak continuity of $f$, we have

$$
f(\bar{t}, y) \geq 0 \quad \forall y \in C .
$$

Thus, $\bar{t}$ is belong to the solution set of $E P(f, C)$. Let us show $\bar{t} \in \operatorname{Sol}(F, C)$. By $y^{k}=T_{\beta_{k}}\left(x^{k}\right)$, we have

$$
F\left(y^{k}, y\right)+\frac{1}{\beta_{k}}\left\langle y-y^{k}, y^{k}-x^{k}\right\rangle \geq 0 \quad \forall y \in C .
$$

Since $F$ is monotone on $C$, we also have

$$
\frac{1}{\beta_{k}}\left\langle y-y^{k}, y^{k}-x^{k}\right\rangle \geq F\left(y, y^{k}\right) \quad \forall y \in C,
$$

and hence

$$
\frac{1}{\beta_{k_{i}}}\left\langle y-y^{k_{i}}, y^{k_{i}}-x^{k_{i}}\right\rangle \geq F\left(y, y^{k_{i}}\right) .
$$

Since $\left\|y^{k_{i}}-x^{k_{i}}\right\| \rightarrow 0, y^{k_{i}} \rightarrow \bar{t}$, the lower semicontinuity and convexity of $F(y, \cdot)$ for all $y \in C$, we have $F(y, \bar{t}) \leq 0$. So, from the convexity of $F(y, \cdot)$, for all $\lambda \in(0,1]$, we have

$$
\begin{aligned}
0 & =F(\lambda y+(1-\lambda) \bar{t}, \lambda y+(1-\lambda) \bar{t}) \\
& \leq \lambda F(\lambda y+(1-\lambda) \bar{t}, y)+(1-\lambda) F(\lambda y+(1-\lambda) \bar{t}, \bar{t}) \\
& \leq \lambda F(\lambda y+(1-\lambda) \bar{t}, y)
\end{aligned}
$$

and hence $F(\lambda y+(1-\lambda) \bar{t}, y) \geq 0 \quad \forall y \geq 0$. Let $\lambda \rightarrow 0$ and using the assumption $\left(A_{3}\right)$, we have $F(\bar{t}, y) \geq 0 \forall y \geq 0$ and hence $\bar{t}$ is also belong to the solution set $\operatorname{Sol}(F, C)$. Thus, the subsequences $\left\{x^{k_{i}}\right\},\left\{y^{k_{i}}\right\}$ and $\left\{z^{k_{i}}\right\}$ weakly converge to the same point $\bar{t} \in \operatorname{Sol}(F, C) \cap \operatorname{Sol}(f, C)$.

In order to show that the entire sequence $\left\{x^{k}\right\}$ weakly converges to $\bar{t}$, assume that there is another subsequence $\left\{\bar{x}^{k_{i}}\right\}$ of the sequence $\left\{x^{k}\right\}$ that weakly converges to some $\hat{t} \in \operatorname{Sol}(F, C) \cap \operatorname{Sol}(f, C)$ and $\hat{t} \neq \bar{t}$. Note that from Step 1 it follows that there exists $\lim _{k \rightarrow \infty}\left\|x^{k}-\hat{t}\right\|$ and $\lim _{k \rightarrow \infty}\left\|x^{k}-\bar{t}\right\|$. By the Opial condition, we have

$$
\begin{aligned}
\lim _{k \rightarrow \infty}\left\|x^{k}-\bar{t}\right\| & =\liminf _{i \rightarrow \infty}\left\|x^{k_{i}}-\bar{t}\right\| \\
& <\liminf _{i \rightarrow \infty}\left\|x^{k_{i}}-\hat{t}\right\| \\
& =\lim _{k \rightarrow \infty}\left\|x^{k}-\hat{t}\right\| \\
& =\lim _{i \rightarrow \infty}\left\|\bar{x}^{k_{i}}-\hat{t}\right\| \\
& <\lim _{i \rightarrow \infty}\left\|\bar{x}^{k_{i}}-\bar{t}\right\| \\
& =\lim _{k \rightarrow \infty}\left\|x^{k}-\bar{t}\right\| .
\end{aligned}
$$

This is a contraction and thus $\bar{t}=\hat{t}$. So, the sequence $\left\{x^{k}\right\}$ weakly converges to $\bar{t}$ and hence the sequences $\left\{y^{k}\right\},\left\{z^{k}\right\}$ and $\left\{t^{k}\right\}$ also weakly converges to the same point $\bar{t} \in \operatorname{Sol}(F, C) \cap \operatorname{Sol}(f, C)$. 
Remark 3.2. In the special cases $\alpha_{k}=0$ for all $k \geq 0$ or $g$ is the identity mapping, it follows from (3.3) that $\left\|x^{k+1}-\bar{x}\right\| \leq\left\|x^{k}-\bar{x}\right\|$ for all $\bar{x} \in \operatorname{Sol}(F, C) \cap$ $\operatorname{Sol}(f, C)$. By Lemma 2.6, the sequence $\left\{\operatorname{Pr}_{S o l(F, C) \cap S o l(f, C)}\left(x^{k}\right)\right\}$ strongly converges to some $x^{*} \in \operatorname{Sol}(F, C) \cap \operatorname{Sol}(f, C)$. Set $u^{k}=\operatorname{Pr}_{\operatorname{Sol}(F, C) \cap S o l(f, C)}\left(x^{k}\right)$. Combining

$$
\left\langle\bar{t}-u^{k}, u^{k}-x^{k}\right\rangle \leq 0 \quad \forall k \geq 0,
$$

and

$$
x^{k} \rightarrow \bar{t}, y^{k} \rightarrow \bar{t}, z^{k} \rightarrow \bar{t} \in \operatorname{Sol}(F, C) \cap \operatorname{Sol}(f, C),
$$

we get

$$
\left\langle\bar{t}-x^{*}, x^{*}-\bar{t}\right\rangle \leq 0,
$$

and hence $\bar{t}=x^{*}$. Thus, the sequences $\left\{x^{k}\right\},\left\{y^{k}\right\},\left\{z^{k}\right\}$ and $\left\{t^{k}\right\}$ generated by Algorithm 2.1 weakly converge to the same point $x^{*} \in \operatorname{Sol}(F, C) \cap \operatorname{Sol}(f, C)$, where

$$
x^{*}=\lim _{k \rightarrow \infty} \operatorname{Pr}_{\operatorname{Sol}(F, C) \cap \operatorname{Sol}(f, C)}\left(x^{k}\right) .
$$

Let the sequence $\left\{x^{k}\right\}$ be defined by Algorithm 2.2. Suppose that there does not exist a natural number $k_{0}$ such that $r\left(x^{k}\right)=0$ for all $k \geq k_{0}$. We take a subsequence $\left\{x^{k_{j}}\right\}$ of the sequence $\left\{x^{k}\right\}$ such that

$$
\left\|r\left(y^{k_{j}-1}\right)\right\| \neq 0 \quad \forall j \geq 0 \text {. }
$$

By a same way as the proof of Theorem 3.2 in [5], we also get the following lemma.

Lemma 3.3. The following statements hold.

(a) There exists the smallest nonnegative integer $m_{k_{j}-1}$ such that

$$
f\left(y^{k_{j}-1}-\gamma^{m_{k_{j}-1}} r\left(y^{k_{j}-1}\right), y^{k_{j}-1}\right) \leq-\sigma\left\|r\left(y^{k_{j}-1}\right)\right\|^{2} .
$$

(b) $y^{k_{j}-1} \notin H_{k_{j}-1}$ for all $j \geq 0$.

(c) $w^{k_{j}-1}=\operatorname{Pr}_{C \cap H_{k_{j}-1}}\left(\bar{y}^{k_{j}-1}\right)$, where $\bar{y}^{k_{j}-1}=\operatorname{Pr}_{H_{k_{j}-1}}\left(y^{k_{j}-1}\right)$.

(d) If $\left\|r\left(y^{k}\right)\right\|>0$, then

$$
\begin{aligned}
& \left\|w^{k}-x^{*}\right\|^{2} \leq\left\|y^{k}-x^{*}\right\|^{2}-\left\|w^{k}-\bar{y}^{k}\right\|^{2}-\left(\frac{\gamma^{m_{k}} \sigma}{\left\|v^{k}\right\|\left(1-\gamma^{m_{k}}\right)}\right)^{2}\left\|r\left(y^{k}\right)\right\|^{4} \\
& \text { for all } x^{*} \in \operatorname{Sol}(f, C) \text {. } \\
& \text { (e) If }\left\|r\left(y^{k}\right)\right\|>0 \text {, then } \operatorname{Sol}(f, C) \subseteq C \cap H_{k} .
\end{aligned}
$$

Lemma 3.4. Claim that the sequence $\left\{\left\|x^{k}-x^{*}\right\|\right\}$ is nonincreasing and hence convergent. Moreover, if $\left\|r\left(y^{k}\right)\right\|>0$ for all $k \geq 0$, then we have

$$
\begin{aligned}
\left\|x^{k+1}-x^{*}\right\|^{2} \leq & \left\|x^{k}-x^{*}\right\|^{2}-\left(1-\alpha_{k}\right)\left\|w^{k}-\bar{y}^{k}\right\|^{2} \\
& -\left(1-\alpha_{k}\right)\left(\frac{\gamma^{m_{k}} \sigma}{\left\|v^{k}\right\|\left(1-\gamma^{m_{k}}\right)}\right)^{2}\left\|r\left(y^{k}\right)\right\|^{4},
\end{aligned}
$$

where $\bar{y}^{k}=\operatorname{Pr}_{H_{k}}\left(y^{k}\right)$ and $x^{*} \in \operatorname{Sol}(F, C) \cap \operatorname{Sol}(f, C)$. 
Proof. Using (3.8) and $x^{k+1}=\alpha_{n} x^{k}+\left(1-\alpha_{k}\right) w^{k}$, for each $x^{*} \in \operatorname{Sol}(f, C)$ we have

$$
\begin{aligned}
\left\|x^{k+1}-x^{*}\right\|^{2}= & \left\|\alpha_{k} x^{k}+\left(1-\alpha_{k}\right) w^{k}-x^{*}\right\|^{2} \\
\leq & \alpha_{k}\left\|x^{k}-x^{*}\right\|^{2}+\left(1-\alpha_{k}\right)\left\|w^{k}-x^{*}\right\|^{2} \\
\leq & \alpha_{n}\left\|x^{k}-x^{*}\right\|^{2}+\left(1-\alpha_{k}\right)\left[\left\|y^{k}-x^{*}\right\|^{2}-\left\|w^{k}-\bar{y}^{k}\right\|^{2}\right. \\
& \left.\quad-\left(\frac{\gamma^{m_{k}} \sigma}{\left\|v^{k}\right\|\left(1-\gamma^{m_{k}}\right)}\right)^{2}\left\|r\left(y^{k}\right)\right\|^{4}\right] \\
\leq & \left\|x^{k}-x^{*}\right\|^{2}-\left(1-\alpha_{k}\right)\left\|w^{k}-\bar{y}^{k}\right\|^{2} \\
& -\left(1-\alpha_{k}\right)\left(\frac{\gamma^{m_{k}} \sigma}{\left\|v^{k}\right\|\left(1-\gamma^{m_{k}}\right)}\right)^{2}\left\|r\left(y^{k}\right)\right\|^{4} .
\end{aligned}
$$

In the case $\left\|r\left(y^{k}\right)\right\|=0$, by Step 2 of Algorithm 2.2, we have $w^{k}=y^{k}$ and

$$
\begin{aligned}
\left\|x^{k+1}-x^{*}\right\| & =\left\|\alpha_{k} x^{k}+\left(1-\alpha_{k}\right) y^{k}-x^{*}\right\| \\
& \leq \alpha_{k}\left\|x^{k}-x^{*}\right\|+\left(1-\alpha_{k}\right)\left\|y^{k}-x^{*}\right\| \\
& \leq \alpha_{k}\left\|x^{k}-x^{*}\right\|+\left(1-\alpha_{k}\right)\left\|x^{k}-x^{*}\right\| \\
& =\left\|x^{k}-x^{*}\right\| .
\end{aligned}
$$

Using this and (3.9), we have

$$
\left\|x^{k+1}-x^{*}\right\| \leq\left\|x^{k}-x^{*}\right\| \quad \forall k \geq 0 .
$$

So the sequence $\left\{\left\|x^{k}-x^{*}\right\|\right\}$ is nonincreasing and hence convergent.

Lemma 3.5. Claim that there exists $c=\lim _{k \rightarrow \infty}\left\|x^{k}-x^{*}\right\|=\lim _{k \rightarrow \infty} \| w^{k}-$ $x^{*} \|$, where $x^{*} \in \operatorname{Sol}(F, C) \cap \operatorname{Sol}(f, C)$. Consequently, the sequences $\left\{x^{k}\right\},\left\{y^{k}\right\}$, $\left\{z^{k}\right\},\left\{v^{k}\right\}$ and $\left\{w^{k}\right\}$ are bounded.

Proof. By Lemma 3.4, there exists

$$
c=\lim _{k \rightarrow \infty}\left\|x^{k}-x^{*}\right\| .
$$

Since Lemma 3.3(e), and the fact that $w^{k}=y^{k}$ if $\left\|r\left(y^{k}\right)\right\|=0$ and $w^{k}=$ $\operatorname{Pr}_{C \cap H_{k}}\left(y^{k}\right)$ if $\left\|r\left(y^{k}\right)\right\| \neq 0$, we have

$$
\left\|w^{k}-x^{*}\right\| \leq\left\|y^{k}-x^{*}\right\| \leq\left\|x^{k}-x^{*}\right\| \quad \forall k \geq 0 .
$$

Hence

$$
\lim _{k \rightarrow \infty}\left\|w^{k}-x^{*}\right\| \leq \lim _{k \rightarrow \infty}\left\|x^{k}-x^{*}\right\|=c .
$$

Using $x^{k+1}=\alpha_{k} x^{k}+\left(1-\alpha_{k}\right) w^{k}$, we have

$$
\begin{aligned}
\left\|x^{k+1}-x^{*}\right\| & =\left\|\alpha_{k} x^{k}+\left(1-\alpha_{k}\right) w^{k}-x^{*}\right\| \\
& \leq \alpha_{k}\left\|x^{k}-x^{*}\right\|+\left(1-\alpha_{k}\right)\left\|w^{k}-x^{*}\right\| .
\end{aligned}
$$


FIXED POINT SOLUTION METHODS FOR SOLVING EQUILIBRIUM PROBLEMS 491

Hence

$$
c \leq \lim _{k \rightarrow \infty}\left\|w^{k}-x^{*}\right\| .
$$

From (3.12) and (3.11), it follows that

$$
c=\lim _{k \rightarrow \infty}\left\|w^{k}-x^{*}\right\| .
$$

Since $z^{k}$ is the unique solution to

$$
\min \left\{f\left(y^{k}, y\right)+\frac{\beta}{2} \| y-\left.y^{k}\right|^{2}: y \in C\right\}
$$

we have

$$
f\left(y^{k}, y\right)+\frac{\beta}{2}\left\|y-y^{k}\right\|^{2} \geq f\left(y^{k}, z^{k}\right)+\frac{\beta}{2}\left\|z^{k}-y^{k}\right\|^{2} \quad \forall y \in C .
$$

Therefore, with $y=y^{k} \in C$, it holds:

$$
0 \geq f\left(y^{k}, z^{k}\right)+\frac{\beta}{2}\left\|z^{k}-y^{k}\right\|^{2} .
$$

Since $f\left(y^{k}, \cdot\right)$ is convex and subdifferentiable on $C$, i.e.,

$$
f\left(y^{k}, z^{k}\right)-f\left(y^{k}, y^{k}\right) \geq\left\langle s^{n}, z^{k}-y^{k}\right\rangle \quad \forall s^{k} \in \partial f\left(y^{k}, \cdot\right)\left(y^{k}\right),
$$

we have $f\left(y^{k}, z^{k}\right) \geq\left\langle s^{k}, z^{k}-y^{k}\right\rangle$. Then, using (3.13) we obtain

$$
\left\langle s^{k}, z^{k}-y^{k}\right\rangle+\frac{\beta}{2}\left\|y^{k}-z^{k}\right\|^{2} \leq 0 .
$$

This implies that

$$
\frac{1}{\beta^{2}}\left\|s^{k}\right\|^{2}+\frac{2}{\beta}\left\langle s^{k}, z^{k}-y^{k}\right\rangle+\left\|y^{k}-z^{k}\right\|^{2} \leq \frac{1}{\beta^{2}}\left\|s^{k}\right\|^{2} .
$$

Hence

$$
\left\|y^{k}-z^{k}+\frac{1}{\beta} s^{k}\right\| \leq \frac{1}{\beta}\left\|s^{k}\right\| .
$$

From the assumption (iv) and (3.10), it implies that the sequence $\left\{s^{k}\right\}$ is bounded. Then, it follows from (3.14) that $\left\{y^{k}\right\}$ is bounded and hence $\bar{z}^{k}=$ $y^{k}-\gamma^{m_{k}}\left(y^{k}-z^{k}\right)$ is also bounded. Also the sequences $\left\{v^{k}\right\}$ and $\left\{w^{k}\right\}$ are bounded.

Lemma 3.6. Let $x^{*} \in \operatorname{Sol}(F, C) \cap \operatorname{Sol}(f, C)$. Assume that if the sequence $\left\{s^{k}\right\}$ is bounded then $\left\{v^{k}\right\}$ is also bounded, where $v^{k} \in \partial f\left(s^{k}, \cdot\right)\left(s^{k}\right)$. Then, we have

$$
\begin{aligned}
\left\|x^{k_{j+1}}-x^{*}\right\|^{2} \leq \| & x^{k_{j}}-x^{*}\left\|^{2}-(1-b)\right\| w^{k_{j}+p_{j}}-\bar{y}^{k_{j}+p_{j}} \|^{2} \\
& -(1-b)\left(\frac{\gamma^{m_{k_{j}+p_{j}}} \sigma}{M\left(1-\gamma^{m_{k_{j}+p_{j}}}\right)}\right)^{2}\left\|r\left(y^{k_{j}+p_{j}}\right)\right\|^{4}
\end{aligned}
$$

where $0<a \leq \alpha_{n} \leq b<1, p_{j}=k_{j+1}-k_{j}-1, r\left(y^{k_{j}+i}\right)=0 \forall i=0,1, \ldots, p_{j}-1$, $r\left(y^{k_{j}+p_{j}}\right) \neq 0, \bar{y}^{k_{j}+p_{k}}=\operatorname{Pr}_{H_{k_{j}+p_{j}}}\left(y^{k_{j}+p_{j}}\right)$, and the sequence $\left\{v^{k}\right\}$ is uniformly bounded by $M>0$. 
Proof. Using the assumption and Lemma 3.5, there exists $M>0$ such that $\left\|v^{n}\right\| \leq M$ for all $n \geq 0$. Then, if $k_{j+1}=k_{j}+1$, then the inequality (3.15) is clear from Lemma 3.4. Otherwise, we suppose that there exists a positive integer $p_{j}$ such that $k_{j}+p_{j}+1=n_{j+1}$ and $\left\|r\left(x^{k_{j}+i}\right)\right\|=0$ for all $i=0,1, \ldots, p_{j}-1$. By the assumptions $0<a \leq \alpha_{k} \leq b<1,\left\|r\left(y^{k_{j}+p_{j}}\right)\right\|>0$ and Lemma 3.4, we have

$$
\begin{aligned}
& \left\|x^{k_{j+1}}-x^{*}\right\|^{2}=\left\|x^{k_{j}+p_{j}+1}-x^{*}\right\|^{2} \\
& \leq\left\|x^{k_{j}+p_{j}}-x^{*}\right\|^{2}-\left(1-\alpha_{k_{j}+p_{j}}\right)\left\|w^{k_{j}+p_{j}}-\bar{y}^{k_{j}+p_{j}}\right\|^{2} \\
& -\left(1-\alpha_{k_{j}+p_{j}}\right)\left(\frac{\gamma^{m_{k_{j}+p_{j}}} \sigma}{M\left(1-\gamma^{m_{k_{j}+p_{j}}}\right)}\right)^{2}\left\|r\left(y^{k_{j}+p_{j}}\right)\right\|^{4} \\
& \leq\left\|\alpha_{k_{j}+p_{j}-1} x^{k_{j}+p_{j}-1}+\left(1-\alpha_{k_{j}+p_{j}-1}\right) w^{k_{j}+p_{j}-1}-x^{*}\right\|^{2} \\
& -(1-b)\left\|w^{k_{j}+p_{j}}-\bar{y}^{k_{j}+p_{j}}\right\|^{2} \\
& -(1-b)\left(\frac{\gamma^{m_{k_{j}+p_{j}}} \sigma}{M\left(1-\gamma^{m_{k_{j}+p_{j}}}\right)}\right)^{2}\left\|r\left(x^{k_{j}+p_{j}}\right)\right\|^{4} \\
& \leq \alpha_{k_{j}+p_{j}-1}\left\|x^{k_{j}+p_{j}-1}-x^{*}\right\|^{2}+\left(1-\alpha_{k_{j}+p_{j}-1}\right)\left\|w^{k_{j}+p_{j}-1}-x^{*}\right\|^{2} \\
& -(1-b)\left\|w^{k_{j}+p_{j}}-\bar{y}^{k_{j}+p_{j}}\right\|^{2} \\
& -(1-b)\left(\frac{\gamma^{m_{k_{j}+p_{j}}} \sigma}{M\left(1-\gamma^{m_{k_{j}+p_{j}}}\right)}\right)^{2}\left\|r\left(y^{k_{j}+p_{j}}\right)\right\|^{4} \\
& \leq \alpha_{k_{j}+p_{j}-1}\left\|x^{k_{j}+p_{j}-1}-x^{*}\right\|^{2}+\left(1-\alpha_{k_{j}+p_{j}-1}\right)\left\|y^{k_{j}+p_{j}-1}-x^{*}\right\|^{2} \\
& -(1-b)\left\|w^{k_{j}+p_{j}}-\bar{y}^{k_{j}+p_{j}}\right\|^{2} \\
& -(1-b)\left(\frac{\gamma^{m_{k_{j}+p_{j}} \sigma}}{M\left(1-\gamma^{m_{k_{j}+p_{j}}}\right)}\right)^{2}\left\|r\left(y^{k_{j}+p_{j}}\right)\right\|^{4} \\
& \leq\left\|x^{k_{j}+p_{j}-1}-x^{*}\right\|^{2}-(1-b)\left\|w^{k_{j}+p_{j}}-\bar{y}^{k_{j}+p_{j}}\right\|^{2} \\
& -(1-b)\left(\frac{\gamma^{m_{k_{j}+p_{j}} \sigma}}{M\left(1-\gamma^{m_{k_{j}+p_{j}}}\right)}\right)^{2}\left\|r\left(y^{k_{j}+p_{j}}\right)\right\|^{4} \\
& \leq \cdots \\
& \leq\left\|x^{k_{j}}-x^{*}\right\|^{2}-(1-b)\left\|w^{k_{j}+p_{j}}-\bar{y}^{k_{j}+p_{j}}\right\|^{2} \\
& -(1-b)\left(\frac{\gamma^{m_{k_{j}+p_{j}} \sigma}}{M\left(1-\gamma^{m_{k_{j}+p_{j}}}\right)}\right)^{2}\left\|r\left(y^{k_{j}+p_{j}}\right)\right\|^{4} \text {. }
\end{aligned}
$$

This implies (3.15).

Now, we turn to the main convergence result of Algorithm 2.2.

Theorem 3.7. Suppose that the bifunction $f$ satisfy the conditions $A_{1}-$ $A_{6}$, if the sequence $\left\{s^{k}\right\}$ is bounded then $\left\{v^{k}\right\}$ is also bounded, where $v^{k} \in$ 
FIXED POINT SOLUTION METHODS FOR SOLVING EQUILIBRIUM PROBLEMS 493 $\partial f\left(s^{k}, \cdot\right)\left(s^{k}\right)$, and the parameters satisfy the following conditions:

$$
\left\{\begin{array}{l}
0<a \leq \alpha_{k} \leq b<1 \quad \forall k \geq 0 \\
\beta=\liminf _{k \rightarrow \infty} \lambda_{k}>0 \\
0<\sigma<\frac{\beta}{2} \\
0<\gamma<1 \\
\liminf _{k \rightarrow \infty} \beta_{k}>0,0<\beta_{k} \quad \forall k \geq 0 .
\end{array}\right.
$$

Then, the sequences $\left\{x^{k}\right\},\left\{y^{k}\right\}$ and $\left\{w^{k}\right\}$ generated by Algorithm 2.2 weakly converge to the same point $x^{*} \in \operatorname{Sol}(F, C) \cap \operatorname{Sol}(f, C)$, where

$$
x^{*}=\lim _{k \rightarrow \infty} \operatorname{Pr}_{\operatorname{Sol}(F, C) \cap \operatorname{Sol}(f, C)}\left(x^{k}\right) .
$$

Proof. We consider two cases:

Case a) There is no natural number $k_{0}$ such that $r\left(y^{k}\right)=0$ for all $k \geq k_{0}$. Using Lemma 3.6 and Lemma 3.5, we obtain that the sequence $\left\{v^{k}\right\}$ is bounded by $M>0$ and

$$
\left\|x^{k_{j+1}}-x^{*}\right\|^{2} \leq\left\|x^{k_{j}}-x^{*}\right\|^{2}-(1-b)\left(\frac{\gamma^{m_{k_{j}+p_{j}} \sigma}}{M\left(1-\gamma^{m_{k_{j}+p_{j}}}\right)}\right)^{2}\left\|r\left(y^{k_{j}+p_{j}}\right)\right\|^{4},
$$

with $p_{j}=k_{j+1}-k_{j}-1$. Since $\left\{\left\|x^{k}-x^{*}\right\|\right\}$ is convergent, it is easy to see that

$$
\lim _{j \rightarrow \infty} \gamma^{m_{k_{j}+p_{j}}}\left\|r\left(y^{k_{j}+p_{j}}\right)\right\|=0 .
$$

Case $\left.a_{1}\right) \limsup _{j \rightarrow \infty} \gamma^{m_{k_{j}+p_{j}}}>0$.

In this case it follows that $\liminf _{k \rightarrow \infty}\left\|r\left(y^{k_{j}+p_{j}}\right)\right\|=0$. Since $\left\{x^{k_{j}+p_{j}}\right\}$ is bounded, there exists an accumulation point $\bar{x}$ of $\left\{x^{k_{j}+p_{j}}\right\}$. In other words, a subsequence $\left\{x^{k_{j_{i}}+p_{j_{i}}}\right\}$ weakly converges to some $\bar{x}$, as $i \rightarrow \infty$ such that $r(\bar{x})=0$. It means that $\bar{x} \in \operatorname{Sol}(f, C)$.

Case $\left.a_{2}\right) \lim _{j \rightarrow \infty} \gamma^{m_{k_{j}+p_{j}}}=0$.

Since $\left\{\left\|x^{k_{j}+p_{j}}-x^{*}\right\|\right\}$ is convergent and Lemma 3.5, there are subsequences $\left\{x^{k_{j_{i}}+p_{j_{i}}}\right\}$ of $\left\{x^{k_{j}+p_{j}}\right\}$ and $\left\{y^{k_{j_{i}}+p_{j_{i}}}\right\}$ of $\left\{y^{k_{j}+p_{j}}\right\}$ such that $\left\{x^{k_{j_{i}}+p_{j_{i}}}\right\}$ weakly converges to $\bar{x}$ and $\left\{y^{k_{j_{i}}+p_{j_{i}}}\right\}$ weakly converges to $\bar{y}$ as $i \rightarrow \infty$. Since $m_{k_{j}+p_{j}}$ is the smallest nonnegative integer, $m_{k_{j}+p_{j}}-1$ does not satisfy $(2.10)$. Hence, we have

$$
f\left(x^{k_{j_{i}}+p_{j_{i}}}-\gamma^{m_{k_{j_{i}}+p_{j_{i}}}-1} r\left(y^{k_{j_{i}}+p_{j_{i}}}\right), z^{k_{j_{i}}+p_{j_{i}}}\right)>-\sigma\left\|r\left(y^{k_{j_{i}}+p_{j_{i}}}\right)\right\|^{2} .
$$

Passing onto the limit, as $i \rightarrow \infty$ and using the continuity of $f$, we have

$$
f(\bar{x}, \bar{y}) \geq-\sigma\|r(\bar{x})\|^{2},
$$

where $r(\bar{x})=\bar{x}-\bar{y}$. It follows from (2.10) that

$$
f\left(x^{k_{j_{i}}+p_{j_{i}}}-\gamma^{m_{k_{j_{i}}+p_{j_{i}}}} r\left(y^{k_{j_{i}}+p_{j_{i}}}\right), y^{k_{j_{i}}+p_{j_{i}}}\right)+\frac{\beta}{2}\left\|r\left(y^{k_{j_{i}}+p_{j_{i}}}\right)\right\|^{2} \leq 0 .
$$


Passing onto the limit, as $i \rightarrow \infty$ ( $f$ is continuous), we obtain

$$
f(\bar{x}, \bar{y})+\frac{\beta}{2}\|r(\bar{x})\|^{2} \leq 0 .
$$

Combining this with (3.17), we have

$$
\sigma\|r(\bar{x})\|^{2} \geq-f(\bar{x}, \bar{y}) \geq \frac{\beta}{2}\|r(\bar{x})\|^{2},
$$

which implies that $r(\bar{x})=0$, and hence $\bar{x}=\bar{y} \in \operatorname{Sol}(f, C)$. Thus, every weak cluster point of the sequence $\left\{x^{k_{j}+p_{j}}\right\}$ is a solution of the problem $E P(f, C)$.

Now we show that every weak cluster point of $\left\{x^{k_{j}+p_{j}}\right\}$ is long to the set $\operatorname{Sol}(F, C)$. Suppose that the subsequences $\left\{x^{k_{j_{i}}+p_{j_{i}}}\right\}$ of $\left\{x^{k_{j}+p_{j}}\right\}$ and $\left\{y^{k_{j_{i}}+p_{j_{i}}}\right\}$ of $\left\{y^{k_{j}+p_{j}}\right\}$ such that $\left\{x^{k_{j_{i}}+p_{j_{i}}}\right\}$ weakly converges to $\bar{x}$ and $\left\{y^{k_{j_{i}}+p_{j_{i}}}\right\}$ weakly converges to $\bar{y}$ as $i \rightarrow \infty$. By $y^{k}=T_{\beta_{k}}\left(x^{k}\right)$, we have

$$
F\left(y^{k}, y\right)+\frac{1}{\beta_{k}}\left\langle y-y^{k}, y^{k}-x^{k}\right\rangle \geq 0 \quad \forall y \in C .
$$

Since $F$ is monotone on $C$, we get

and hence

$$
\frac{1}{\beta_{k}}\left\langle y-y^{k}, y^{k}-x^{k}\right\rangle \geq F\left(y, y^{k}\right) \quad \forall y \in C,
$$

$$
\frac{1}{\beta_{k_{j_{i}}}}\left\langle y-y^{k_{j_{i}}}, y^{k_{j_{i}}}-x^{k_{j_{i}}}\right\rangle \geq F\left(y, y^{k_{j_{i}}}\right) \quad \forall y \in C .
$$

Since $\left\|y^{k_{j_{i}}}-x^{k_{j_{i}}}\right\| \rightarrow 0$ as $i \rightarrow \infty$, the lower semicontinuity and the convexity of $F(y, \cdot)$ for all $y \in C$, we have $F(y, \bar{x}) \leq 0$. So, for all $\lambda \in(0,1]$ we have

$$
\begin{aligned}
0 & =F(\lambda y+(1-\lambda) \bar{x}, \lambda y+(1-\lambda) \bar{x}) \\
& \leq \lambda F(\lambda y+(1-\lambda) \bar{x}, y)+(1-\lambda) F(\lambda y+(1-\lambda) \bar{x}, \bar{x}) \\
& \leq \lambda F(\lambda y+(1-\lambda) \bar{x}, y),
\end{aligned}
$$

and hence $F(\lambda y+(1-\lambda) \bar{x}, y) \geq 0$ for all $y \in C$. Let $\lambda \rightarrow 0$, we get $F(\bar{x}, y) \geq 0$ for all $y \in C$ and so $\bar{x} \in \operatorname{Sol}(F, C)$. Thus, every weak cluster point of the sequence $\left\{x^{k_{j}+p_{j}}\right\}$ is belong to the set $\operatorname{Sol}(F, C)$.

In order to show that the entire sequence $\left\{x^{k}\right\}$ weakly converges to $\bar{x}$. Assume that there is another subsequence $\left\{\bar{x}^{k_{i}}\right\}$ which weakly converges to some $\hat{x} \in \operatorname{Sol}(F, C) \cap \operatorname{Sol}(f, C)$ and $\bar{x} \neq \hat{x}$. By the Opial condition and Lemma 3.5, we have

$$
\begin{aligned}
\lim _{k \rightarrow \infty}\left\|x^{k}-\bar{x}\right\| & =\liminf _{i \rightarrow \infty}\left\|x^{k_{j_{i}}}-\bar{x}\right\| \\
& <\liminf _{i \rightarrow \infty}\left\|x^{k_{j_{i}}}-\hat{x}\right\| \\
& =\lim _{k \rightarrow \infty}\left\|x^{k}-\hat{x}\right\| \\
& =\lim _{i \rightarrow \infty}\left\|\bar{x}^{k_{i}}-\hat{x}\right\| \\
& <\lim _{i \rightarrow \infty}\left\|\bar{x}^{k_{i}}-\bar{x}\right\|
\end{aligned}
$$


FIXED POINT SOLUTION METHODS FOR SOLVING EQUILIBRIUM PROBLEMS 495

$$
=\lim _{k \rightarrow \infty}\left\|x^{k}-\bar{x}\right\| .
$$

This is a contraction and thus $\bar{x}=\hat{x}$. So the subsequence $\left\{x^{k}\right\}$ weakly converges to $\bar{x} \in \operatorname{Sol}(F, C) \cap \operatorname{Sol}(f, C)$. Then, the sequences $\left\{y^{k}\right\},\left\{z^{k}\right\}$ and $\left\{w^{k}\right\}$ also weakly converge to the same point $\bar{x} \in \operatorname{Sol}(F, C) \cap \operatorname{Sol}(f, C)$.

Now we will prove that the sequences $\left\{x^{k}\right\},\left\{y^{k}\right\}$ and $\left\{w^{k}\right\}$ weakly converge to $\bar{x}$, where

$$
\bar{x}=\lim _{k \rightarrow \infty} \operatorname{Pr}_{S o l(F, C) \cap S o l(f, C)}\left(x^{k}\right) .
$$

Indeed, we suppose that $t^{k}:=\operatorname{Pr}_{\operatorname{Sol}(F, C) \cap S o l(f, C)}\left(x^{k}\right)$ and $x^{k} \rightarrow \bar{x}$. By the definition of $\operatorname{Pr}_{C}(\cdot)$, we have

$$
\left\langle t^{k}-x^{k}, t^{k}-x\right\rangle \leq 0 \quad \forall x \in \operatorname{Sol}(F, C) \cap \operatorname{Sol}(f, C) .
$$

It follows from Lemma 3.4 that

$$
\left\|x^{k+1}-x^{*}\right\| \leq\left\|x^{k}-x^{*}\right\| \quad \forall x^{*} \in \operatorname{Sol}(F, C) \cap \operatorname{Sol}(f, C) .
$$

Then, by Lemma 2.6, we have

(3.19) $t^{k}=\operatorname{Pr}_{\operatorname{Sol}(F, C) \cap \operatorname{Sol}(f, C)}\left(x^{k}\right) \rightarrow \hat{x} \in \operatorname{Sol}(F, C) \cap \operatorname{Sol}(f, C)$ as $k \rightarrow \infty$.

Passing to the limit in (3.18) and combining this with (3.19), we have

$$
\langle\hat{x}-\bar{x}, \hat{x}-x\rangle \leq 0 \quad \forall x \in \operatorname{Sol}(F, C) \cap \operatorname{Sol}(f, C) .
$$

This means that $\bar{x}=\hat{x}$ and $\bar{x}=\lim _{k \rightarrow \infty} \operatorname{Pr}_{\operatorname{Sol}(F, C) \cap \operatorname{Sol}(f, C)}\left(x^{k}\right)$. Thus, both sequences $\left\{y^{k}\right\}$ and $\left\{w^{k}\right\}$ weakly converge to $\bar{x}$, where

$$
\bar{x}=\lim _{k \rightarrow \infty} \operatorname{Pr}_{\operatorname{Sol}(F, C) \cap \operatorname{Sol}(f, C)}\left(x^{k}\right) .
$$

Case b) There exists $k_{0}$ such that $r\left(y^{k}\right)=0$ for all $k \geq k_{0}$. Thus $x^{k} \in \operatorname{Sol}(f, C)$ for all $k \geq k_{0}$ and Algorithm 2.2 becomes the viscosity approximation algorithm proposed by Takahashi and Takahashi in [21]. Then, the iteration sequences $\left\{x^{k}\right\}$ and $\left\{y^{k}\right\}$ strongly converge to the common solution point $x^{*} \in \operatorname{Sol}(F, C) \cap$ $\operatorname{Sol}(f, C)$, where

$$
x^{*}=\lim _{k \rightarrow \infty} \operatorname{Pr}_{\operatorname{Sol}(F, C) \cap S o l(f, C)}\left(x^{k}\right) .
$$

The proof is completed.

\section{Applications to variational inequalities}

Let $C$ is a nonempty, convex and subset of $\mathcal{H}, G$ and $H$ be functions from $C$ into $\mathcal{H}, \varphi: C \rightarrow \mathcal{R}$ and $\phi: C \rightarrow \mathcal{R}$ be proper, continuous and convex functions. We consider the generalized variational inequalities formulated as follows

$V I(G, C)$ Find $x^{*} \in C$ such that $\left\langle G\left(x^{*}\right), x-x^{*}\right\rangle+\varphi(x)-\varphi\left(x^{*}\right) \geq 0 \quad \forall x \in C$, and

$V I(H, C) \quad$ Find $\bar{x} \in C$ such that $\langle H(\bar{x}), x-\bar{x}\rangle+\phi(x)-\phi(\bar{x}) \geq 0 \quad \forall x \in C$. 
We consider the problem which is to a common point of the solution set of the problem $V I(G, C)$ (shortly $S V I(G, C)$ ) and the solution set of the problem $V I(H, C)$ (shortly $S V I(H, C))$. It details that

$$
\text { Find } x^{*} \in S V I(G, C) \cap S V I(H, C) \text {. }
$$

Let $F: C \times C \rightarrow \mathcal{R}$ be defined by $F(x, y):=\langle G(x), y-x\rangle+\varphi(y)-\varphi(x)$, and $f: C \times C \rightarrow \mathcal{R}$ such that $f(x, y):=\langle H(x), y-x\rangle+\phi(y)-\phi(x)$. Then, the problem (4.1) can be written in the form of the problem (1.1).

Let $G: C \rightarrow \mathcal{H}$. The mapping $G$ is called

(i) monotone on $C$ if

$$
\langle G(x)-G(y), x-y\rangle \geq 0 \quad \forall x, y \in C ;
$$

(ii) pseudomonotone on $C$ if

$$
\langle G(y), x-y\rangle \geq 0 \text { implies }\langle G(x), x-y\rangle \geq 0 \quad \forall x, y \in C ;
$$

(iii) Lipschitz continuous on $C$ with constant $L>0$ if

$$
\|G(x)-G(y)\| \leq L\|x-y\| \quad \forall x, y \in C .
$$

It is easy to see that $G$ is pseudomonotone ( $L$-Lipschitz continuous) on $C$ if and only if $F$ is pseudomonotone (corresponding: Lipschitz-type continuous with constants $c_{1}=c_{2}=\frac{L}{2}$ ) on $C$. Then, Algorithm 2.1 applied to solve the problem (4.1) can be described as follows:

Algorithm 4.1. Step 0. Choose $x^{0} \in C, k:=0$, positive sequences $\left\{\lambda_{k}\right\},\left\{\beta_{k}\right\}$ and $\left\{\alpha_{k}\right\}$ such that $\alpha_{k} \in[0,1]$ for all $k \geq 0$.

Step 1 . Solve the auxiliary variational inequalities and the strongly convex programs:

$$
\begin{aligned}
& \left\langle G\left(y^{k}\right), y-y^{k}\right\rangle+\varphi(y)-\varphi\left(y^{k}\right)+\frac{1}{\beta_{k}}\left\langle y-y^{k}, y^{k}-x^{k}\right\rangle \geq 0 \quad \forall y \in C, \\
& z^{k}=\operatorname{argmin}\left\{\lambda_{k}\left\langle H\left(y^{k}\right), y-y^{k}\right\rangle+\lambda_{k} \phi(y)+\frac{1}{2}\left\|z-y^{k}\right\|^{2}: y \in C\right\}, \\
& t^{k}=\operatorname{argmin}\left\{\lambda_{k}\left\langle H\left(z^{k}\right), y-y^{k}\right\rangle+\lambda_{k} \phi(y)+\frac{1}{2}\left\|t-y^{k}\right\|^{2}: y \in C\right\}, \\
& x^{k+1}:=\alpha_{k} g\left(x^{k}\right)+\left(1-\alpha_{k}\right) t^{k} . \\
& \text { If } y^{k}=x^{k} \text { and } z^{k}=y^{k} \text { then STOP. Otherwise, go to Step 2. }
\end{aligned}
$$

Step 2. Set $k:=k+1$, and return to Step 1 .

Similar to Theorems 3.1, the convergence of Algorithm 4.1 is presented as the following:

Theorem 4.2. Let $G: C \rightarrow \mathcal{H}$ be monotone and lower semicontinuous, $H: C \rightarrow \mathcal{H}$ be pseudomonotone and Lipschitz continuous with constant $L>0$, two convex functions $\varphi, \phi: C \rightarrow \mathcal{R}$, and $S V I(G, C) \cap S V I(H, C) \neq \emptyset$. Under certain conditions (3.1) with $c_{1}=c_{2}=\frac{L}{2}$, the sequences $\left\{x^{k}\right\},\left\{y^{k}\right\},\left\{z^{k}\right\}$ 
FIXED POINT SOLUTION METHODS FOR SOLVING EQUILIBRIUM PROBLEMS 497

and $\left\{t^{k}\right\}$ generated by Algorithm 4.1 weakly converge to the same point $x^{*} \in$ $S V I(G, C) \cap S V I(H, C)$. In the special case $\alpha_{k}=0$ for all $k \geq 0$ or $g$ is the identity mapping, the sequences weakly converge to the same point $x^{*} \in$ $\operatorname{Sol}(F, C) \cap \operatorname{Sol}(f, C)$, where

$$
x^{*}=\lim _{k \rightarrow \infty} \operatorname{Pr}_{S V I(G, C) \cap S V I(H, C)}\left(x^{k}\right) .
$$

By applying Algorithm 2.2 for the problem (4.1), we have the following.

Algorithm 4.3. Step 0 . Choose $x^{0} \in C, k:=0, \gamma \in(0,1)$, positive sequences $\left\{\lambda_{k}\right\},\left\{\beta_{k}\right\}$ and $\left\{\alpha_{k}\right\}$ such that $\alpha_{k} \in[0,1]$ for all $k \geq 0$. Take $\sigma \in\left(0, \frac{\beta}{2}\right)$.

Step 1. Solve the auxiliary variational inequalities

$$
\left\langle G\left(y^{k}\right), y-y^{k}\right\rangle+\varphi(y)-\varphi\left(y^{k}\right)+\frac{1}{\beta_{k}}\left\langle y-y^{k}, y^{k}-x^{k}\right\rangle \geq 0 \quad \forall y \in C,
$$

Step 2. Solve the strongly convex program:

$z^{k}=\operatorname{argmin}\left\{\lambda_{k}\left\langle H\left(y^{k}\right), y-y^{k}\right\rangle+\lambda_{k} \phi(y)+\frac{1}{2}\left\|z-y^{k}\right\|^{2}: y \in C\right\}$,

If $y^{k}=x^{k}$ and $z^{k}=y^{k}$ then STOP.

If $y^{k} \neq x^{k}$ and $z^{k}=y^{k}$ then set $w^{k}=y^{k}$

and go to Step 4. Otherwise, go to Step 3.

Step 3. Find the smallest nonnegative integer $m_{k}$ such that

$$
\begin{aligned}
& \left(1-\gamma^{m_{k}}\right)\left\langle H\left(\bar{z}^{k}\right), r\left(y^{k}\right)\right\rangle+\phi\left(\bar{z}^{k}\right)-\phi\left(z^{k}\right) \geq \sigma\left\|r\left(y^{k}\right)\right\|^{2}, \\
& \text { where } r\left(y^{k}\right):=y^{k}-z^{k} . \\
& \text { Set } \bar{z}^{k}=y^{k}-\gamma^{m_{k}} r\left(y^{k}\right) . \text { Compute } w^{k}:=\operatorname{Pr}_{C \cap H_{k}}\left(x^{k}\right), \\
& H_{k}:=\left\{x \in \mathcal{H}:\left\langle H\left(\bar{z}^{k}\right), x-\bar{z}^{k}\right\rangle \leq 0\right\} .
\end{aligned}
$$

Step 4. Compute $x^{k+1}=\alpha_{k} x^{k}+\left(1-\alpha_{k}\right) w^{k}$.

Set $k:=k+1$, and return to Step 1 .

As in Theorem 3.7, we give the convergent results of Algorithm 4.3 as the following.

Theorem 4.4. Let $G: C \rightarrow \mathcal{H}$ be monotone and lower semicontinuous, $H$ : $C \rightarrow \mathcal{H}$ be pseudomonotone and lower semicontinuous, two convex functions $\varphi, \phi: C \rightarrow \mathcal{R}$, and $S V I(G, C) \cap S V I(H, C) \neq \emptyset$. Under certain conditions (3.16), the sequences $\left\{x^{k}\right\},\left\{y^{k}\right\}$ and $\left\{w^{k}\right\}$ generated by Algorithm 4.3 weakly converge to the same point $x^{*} \in S V I(G, C) \cap S V I(H, C)$, where

$$
x^{*}=\lim _{k \rightarrow \infty} \operatorname{Pr}_{S V I(G, C) \cap S V I(H, C)}\left(x^{k}\right) .
$$

\section{References}

[1] P. N. Anh, An LQ regularization method for pseudomonotone equilibrium problems on polyhedra, Vietnam J. Math. 36 (2008), no. 2, 209-228. 
[2] — A logarithmic quadratic regularization method for pseudomonotone equilibrium problems, Acta Math. Vietnam. 34 (2009), no. 2, 183-200.

[3] _ Strong convergence theorems for nonexpansive mappings and Ky Fan inequalities, J. Optim. Theory Appl. 154 (2012), no. 1, 303-320.

[4] _ A hybrid extragradient method extended to fixed point problems and equilibrium problems, Optimization 62 (2013), no. 2, 271-283

[5] P. N. Anh and N. D. Hien, The extragradient-Armijo method for pseudomonotone equilibrium problems and strict pseudocontractions, Fixed Point Theory Appl. 2012 (2012), 82, 16 pp.

[6] P. N. Anh and J. K. Kim, Outer approximation algorithms for pseudomonotone equilibrium problems, Comp. Math. Appl. 61 (2011), no. 9, 2588-2595.

[7] P. N. Anh, J. K. Kim, and J. M. Nam, Strong convergence of an extended extragradient method for equilibrium problems and fixed point problems, J. Korean Math. Soc. 49 (2012), no. 1 187-200.

[8] P. N. Anh and D. X. Son, A new method for a finite family of pseudocontractions and equilibrium problems, J. Appl. Math. Inform. 29 (2011), no. 5-6, 1179-1191.

[9] E. Blum and W. Oettli, From optimization and variational inequality to equilibrium problems, Math. Student 63 (1994), no. 1-4, 123-145.

[10] L. C. Ceng, P. Cubiotti, and J. C. Yao, An implicit iterative scheme for monotone variational inequalities and fixed point problems, Nonlinear Anal. 69 (2008), no. 8, 24452457.

[11] Y. J. Cho and N. Petrot, On the System of nonlinear mixed implicit equilibrium problems in Hilbert spaces, J. Inequal. Appl. 2010 (2010), Article ID 437976, 12 pages.

[12] P. L. Combettes and S. A. Hirstoaga, Equilibrium programming in Hilbert spaces, J. Nonlinear Convex Anal. 6 (2005), no. 1, 117-136.

[13] M. Fukushima, Equivalent differentiable optimization problems and descent methods for asymmetric variational inequality problems, Math. Program. 53 (1992), no. 1, Ser. A, 99-110.

[14] I. V. Konnov, Combined Relaxation Methods for Variational Inequalities, SpringerVerlag, Berlin, 2000.

[15] _ Application of the proximal point method to nonmonotone equilibrium problems, J. Optim. Theory Appl. 119 (2003), no. 2, 317-333.

[16] G. Mastroeni, On auxiliary principle for equilibrium problems, In: P. Daniele, F. Giannessi, and A. Maugeri (eds.), Nonconvex Optimization and its Applications, Kluwer Academic Publishers, Dordrecht, The Netherlands, 2003.

[17] A. Moudafi, Proximal point algorithm extended to equilibrium problem, J. Nat. Geom. 15 (1999), no. 1-2, 91-100.

[18] T. T. V Nguyen, J. J. Strodiot, and V. H. Nguyen, A bundle method for solving equilibrium problems, Math. Program. 116 (2009), 529-552.

[19] M. A. Noor, Auxiliary principle technique for equilibrium problems, J. Optim. Theory Appl. 122 (2004), no. 2, 371-386.

[20] T. D. Quoc, P. N. Anh, and L. D. Muu, Dual extragradient algorithms extended to equilibrium problems, J. Global Optim. 52 (2012), no. 1, 139-159.

[21] S. Takahashi and W. Takahashi, Viscosity approximation methods for equilibrium problems and fixed point problems in Hilbert spaces, J. Math. Anal. Appl. 331 (2007), no. $1,506-515$.

[22] S. Takahashi and M. Toyoda, Weakly convergence theorems for nonexpansive mappings and monotone mappings, J. Optim. Theory Appl. 118 (2013), 417-428.

[23] H. K. Xu, Viscosity approximation methods for nonexpansive mappings, J. Math. Anal. Appl. 298 (2004), no. 1, 279-291. 
FIXED POINT SOLUTION METHODS FOR SOLVING EQUILIBRIUM PROBLEMS 499

PhAm NGOC ANH

Department of Scientific Fundamentals

Posts and Telecommunications Institute of Technology

HANOI, VieTnAM

E-mail address: anhpn@ptit.edu.vn

Nguyen Duc Hien

Department of Natural Sciences

DUY TAN University

DANANG, ViETnAM

E-mail address: nguyenduchien.duytan@gmail.com 